\title{
Chest tube drainage under radiological guidance for pleural effusion and pneumothorax in a tertiary care university teaching hospital: Review of 51 cases
}

\author{
Luce Cantin $M D^{1}$, Carl Chartrand-Lefebvre $M D^{1}$, Luigi Lepanto $\mathrm{MD}^{1}$, David Gianfelice $M D^{1}$, \\ Antoine Rabbat $M D^{2}$, Benoît Aubin $M D^{1}$, Pierre Perreault $M D^{1}$, Renée Déry $M D^{1}$, Michel Lafortune $M D^{1}$
}

L Cantin, C Chartrand-Lefebvre, L Lepanto, et al. Chest tube drainage under radiological guidance for pleural effusion and pneumothorax in a tertiary care university teaching hospital: Review of 51 cases. Can Respir J 2005;12(1):29-33.

BACKGROUND: Chest tube drainage under radiological guidance has been used with increasing frequency as a treatment option for pleural effusions and pneumothoraxes.

OBJECTIVE: To evaluate the safety and usefulness of pleural drainage under radiological guidance for pleural effusion and pneumothorax in a tertiary care university teaching hospital.

METHODS: A retrospective study of cases of chest tube placement under radiological guidance over a 12 -month period in a university hospital.

RESULTS: Fifty-one percutaneous pigtail catheter drainage cases were reviewed (30 patients). Forty-six (90\%) chest tubes were inserted as a first-line treatment. The overall success rate of radiological drainage was $88 \%$. Specific success rates were $92 \%, 85 \%$ and $91 \%$ for loculated pleural effusion, pneumothorax and empyema, respectively. The complications were few and minor.

CONCLUSIONS: Pigtail catheter insertion under radiological guidance is a useful procedure for the treatment of sterile pleural effusion, empyema and pneumothorax. This technique can be used as a first-line procedure in the majority of cases.

Key Words: Chest; Computed tomography; Interventional radiology; Pleura

\section{Drain thoracique sous contrôle radiologique pour épanchement pleural et pneumothorax dans un hôpital universitaire : Revue de 51 cas}

HISTORIQUE : Le drain thoracique posé sous contrôle radiologique a été utilisé de plus en plus souvent comme option thérapeutique pour l'épanchement pleural et le pneumothorax.

OBJECTIF : Évaluer l'innocuité des drains thoraciques installés sous contrôle radiologique pour l'épanchement pleural et le pneumothorax dans un hôpital universitaire de soins tertiaires

MÉTHODE : Étude rétrospective des cas de drains thoraciques posés sous contrôle radiologique au cours d'une période de 12 mois dans un hôpital universitaire.

RÉSULTATS : Cinquante et un cas de drains thoraciques percutanés (cathéters en queue de cochon) ont été passés en revue (30 patients). Quarante-six drains (90\%) ont été posés en traitement de première intention. Le taux de réussite globale des drains installés sous contrôle radiologique a été de $88 \%$. Le taux de réussite spécifique a été de 92, 85 et $91 \%$, respectivement dans les cas d'épanchement pleural loculé, de pneumothorax et d'empyème. Les complications ont été rares et mineures.

CONCLUSION : L'insertion d'un cathéter en queue de cochon sous contrôle radiologique est une intervention utile pour le traitement de l'épanchement pleural stérile, de l'empyème et du pneumothorax. Cette technique peut être utilisée comme intervention de première intention dans la majorité des cas.
Cising hest tube drainage under radiological guidance has been used with increasing frequency as a treatment option for pleural effusions and pneumothoraxes. Previous studies (1-3) have demonstrated that the drainage of parapneumonic effusions with the small tubes used by radiologists have similar success rates compared with drainage with larger tubes. Smaller tubes were better tolerated and suitable for ambulatory treatment in adults $(4,5)$. Good success rates were also reported for sterile pleural effusions and pneumothoraxes in the pediatric population (6). However, in cases of frank empyema, opinions differ as to the efficacy of small-bore catheters used in first-line treatment $(1,6,7)$.

The purpose of the present retrospective study was to evaluate the results of pleural drainage under radiological guidance for pleural effusion and pneumothorax in a tertiary care university teaching hospital (Hôpital Saint-Luc of the
University of Montreal Medical Center, Montreal, Quebec) over a one-year period. More specifically, it was hypothesized that chest tube drainage under radiological guidance is a safe and useful method for pleural effusions, empyema and pneumothoraxes, and that it may often be considered as a first-line procedure.

\section{PATIENTS AND METHODS}

The medical and radiological files of all patients who underwent chest tube placement under radiological guidance over a 12-month period at the Hôpital Saint-Luc of the University of Montreal Medical Center were reviewed. Hôpital Saint-Luc is a reference centre for liver disease and transplantation, as well as a general care centre. All procedures used pigtail catheter chest tubes $(6 \mathrm{~F}$ to $12 \mathrm{~F})$. Nineteen chest tubes were inserted with sonographic guidance and 32 with computed tomography (CT) guidance (16 cases

\footnotetext{
${ }^{1}$ Radiology Department and ${ }^{2}$ Surgery Department, University of Montreal Medical Center, Hôpital Saint-Luc, Montreal, Quebec

Correspondence: Dr Carl Chartrand-Lefebure,1058 Saint-Denis Street, Montreal, Quebec H2X 3J4. Telephone 514-890-8350,

fax 514-412-7359, e-mail chartrandlef@videotron.ca
} 
TABLE 1

Patient $(n=30)$ and procedure $(n=51)$ characteristics

\begin{tabular}{lcc}
\hline Age & $\begin{array}{c}\text { Mean } \\
\text { (years) }\end{array}$ & $\begin{array}{c}\text { Number of } \\
\text { procedures }(\%)\end{array}$ \\
Males & 58.4 & $19(37)$ \\
Females & & $32(63)$ \\
Mechanical ventilation* & $8(16)$ \\
$\begin{array}{l}\text { Coagulopathy* }(\text { INR } 1.2-2.6) \text { or low platelet } \\
\text { count }\left(57 \times 10^{9} / L \text { to } 123 \times 10^{9} / \mathrm{L}\right)\end{array}$ & $22(43)$ \\
Hepatic failure* & \\
Hepatic graft* & $8(16)$ \\
Postsurgery other than liver & $11(22)$ \\
transplantation (mainly coronary bypass) & & $8(16)$ \\
\hline
\end{tabular}

*More than one of these characteristics can occur for a given procedure. INR International normalized ratio

with CT-fluoroscopy). A direct trocar method was usually used for tube insertion; however, less frequently, a modified Seldinger technique was also used. For the modified Seldinger technique, an 18 gauge spinal entry needle was placed into the pleural space, aspiration of pleural fluid or air confirmed the adequate positioning of the needle. A $0.89 \mathrm{~mm}$ Bentson guide wire was coiled into the pleural space. Serial dilation and pigtail catheter insertion were performed using the guide wire. After insertion, the pigtail catheter was connected to a continuous suction drainage system (minus $20 \mathrm{~cm}$ of water) (Pleur-evac, Adult/Pediatric chest drainage unit, Deknatel, USA). Flushing the tube with $15 \mathrm{~mL}$ of sterile saline three times daily was usually prescribed to assure patency of the tube.

Chest tube placement was performed by a staff radiologist or a radiology resident. When performed under CT guidance, the resident was directly supervised by a radiologist. When the placement was done under sonographic guidance, the resident did not have to be directly supervised.

Because the present study was retrospective, the methods of follow-up varied depending on the staff radiologist and the referring clinician. Adequate location of the pigtail catheter was confirmed by fluid return (for pleural effusion) or air (for pneumothorax) at the time of catheter placement. In a minority of cases, a chest radiograph was obtained immediately after the procedure to determine the location and orientation of the catheter in the pleural cavity to serve as a baseline for follow-up. Day-today follow-up of the patient was usually done by the referring physician, including clinical observations, daily tube output measurements and repeated radiographs. The interventional radiology staff would periodically be informed of the clinical and radiographical results; especially in cases with persistent pleural pathology, or catheter plugging or dislodgement. In these cases, the patient would be brought back to the radiology department for additional imaging if needed, usually using CT. A decision was then made on whether the catheter should be replaced or withdrawn, or whether an additional catheter should be placed in a residual pleural loculation.

Success of chest tube drainage was defined as a complete regression of pleural fluid or air after chest tube placement on imaging follow-up, with clinical improvement. Ideally, there should have been no more than $20 \mathrm{~mL}$ of daily drain output. When complete follow-up after chest tube placement was not possible (in cases of patient death due to the underlying pathology, end of treatment in terminally ill patients or patient release from
TABLE 2

Indications for radiologically guided chest tube placement $(n=51)$

\begin{tabular}{lcc}
\hline Indication & Procedures, $\mathbf{n}(\%)$ & Success, $\mathbf{n ~ ( \% ) ~}$ \\
\hline Pleural effusion (other than empyema) & $26(51)$ & $23(88)$ \\
Pneumothorax & $13(25)$ & $11(85)$ \\
Empyema & $11(22)$ & $10(91)$ \\
Anterior mediastinal collection & $1(2)$ & $1(100)$ \\
Total & $51(100)$ & $45(88)$ \\
\hline
\end{tabular}

the institution), the procedure was considered successful if a significant decrease of the pleural effusion or pneumothorax was demonstrated during the available time of follow-up.

\section{RESULTS}

Thirty patients required 51 percutaneous pigtail catheters. Forty-six (90\%) radiological chest tubes were inserted as a first-line treatment. Five (10\%) radiological procedures were done in second intention, after failure of primary surgical drainage. Nineteen procedures were performed on men and 32 were performed on women (mean age 58.4 years, range 31 years to 87 years). Patient characteristics are shown in Table 1. Eight (16\%) procedures were done on patients who were on mechanical ventilation during the intervention. Twenty-two $(43 \%)$ procedures were done on patients who had a prolonged activated partial thromboplastin time (range $35 \mathrm{~s}$ to $99 \mathrm{~s}$ ), international normalized ratio (range 1.2 to 2.6 ) or had low platelets (ranging from $57 \times 10^{9} / \mathrm{L}$ to $123 \times 10^{9} / \mathrm{L}$ ) at the time of the intervention. Eight $(16 \%)$ of the procedures were performed in patients with hepatic failure and $11(22 \%)$ in patients who had undergone liver transplantation. Eight procedures $(16 \%)$ were done following surgery (mainly coronary artery bypass).

The median length of time with the chest tube in place was seven days (mean 10 days), and the median length of stay in the hospital, regardless of chest tube duration, was 30 days (mean 48 days). Forty patients (78\%) had one chest tube inserted, 10 patients $(20 \%)$ had two tubes inserted and one patient had four tubes inserted. Thirty-two catheters were placed in the right side of the chest and 19 on the left side. In cases of pleural effusion drainage, a mean of $560 \mathrm{~mL}$ of fluid was withdrawn (range $20 \mathrm{~mL}$ to $2000 \mathrm{~mL}$ ). In $80 \%$ of the chest tube insertions, no supplementary intervention was done, while $16 \%$ needed repositioning. Doxycycline sclerotherapy was performed in one patient through the pleural pigtail catheter.

Table 2 lists the indications for chest tube placement in the patient group. The most common indication for pleural drainage under imaging was pleural effusion (26 procedures, $51 \%$ ) (Figure 1). Pneumothorax was the indication for 13 procedures (25\%) (Figure 2), empyema for 11 procedures $(22 \%)$ and anterior mediastinal collection for one procedure $(2 \%)$. No hemothorax was drained during this period. Pleural effusions were loculated in 12 of 26 patients (46\%), of which $11(92 \%)$ were successfully drained.

The overall procedure success rate of radiological drainage was $88 \%$. Forty-four of 50 chest tubes inserted for pleural effusion or pneumothorax were successful. There was no statistically significant difference in success rates among the different 

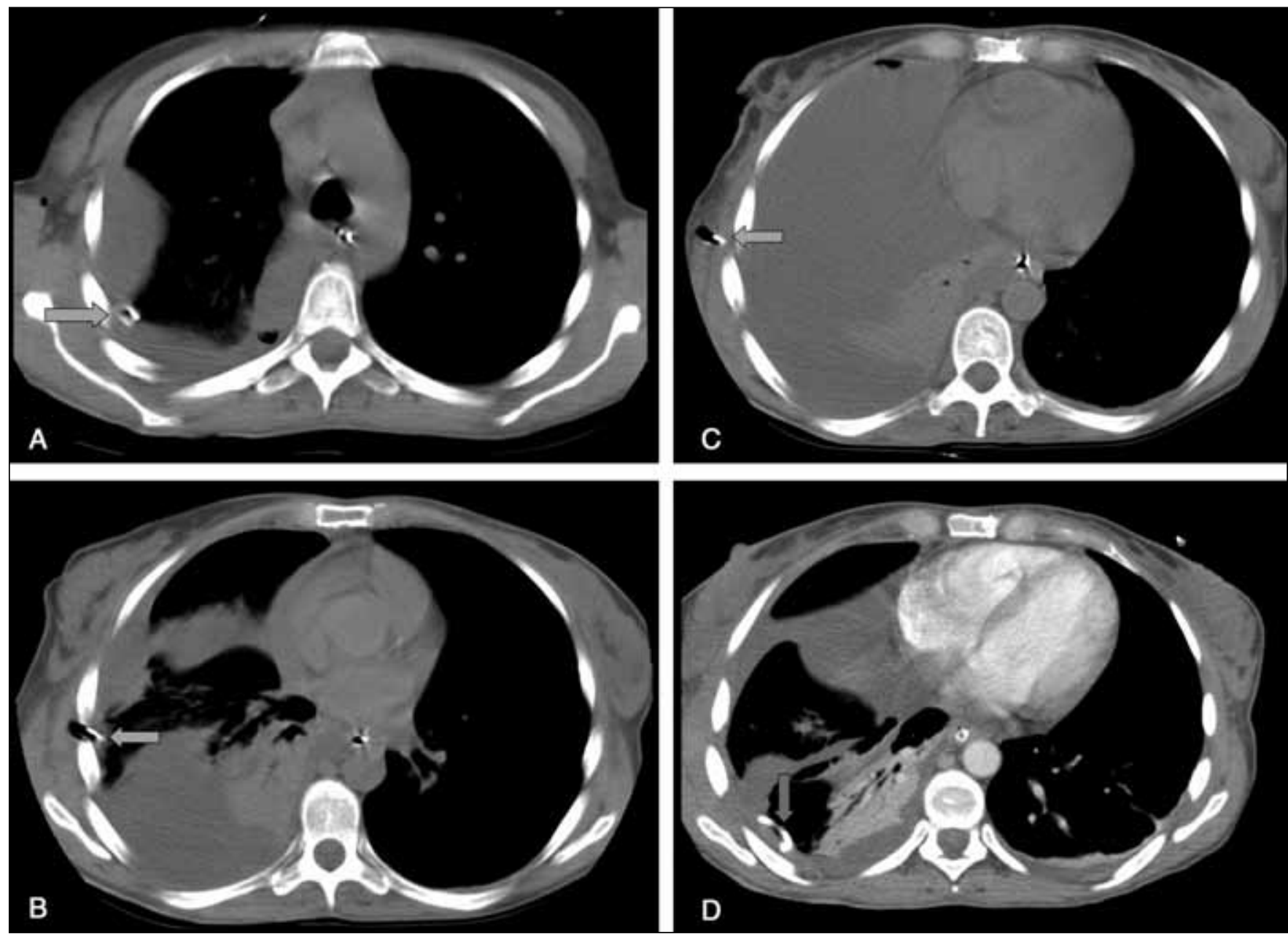

Figure 1) Chest computed tomography (CT) scans from a 38-year-old female with hepatorenal cystic disease. The patient underwent surgical resection of a benign hepatic cyst. A-C Chest CT scans showed a residual postoperative loculated right pleural effusion with the surgical chest tube located at some distance of the nearest major pleural loculation (arrow). D A pigtail catheter (arrow) was installed under CT guidance into a major loculation, with significant improvement on a repeat CT two days later

indications; however, the present study was underpowered to detect slight differences in success rates because of the small numbers in each category.

Image-guided drainage of empyemas involved nine patients and 11 procedures. These included three liver transplantation patients, two postoperative (one thoracotomy and one adrenalectomy) patients, one patient with liver cirrhosis, and one patient with severe dilated cardiomyopathy and end-stage renal failure. In seven patients, organisms were cultured from the fluid; in the remainder, the pleural fluid was described as purulent. Two of these patients each had two pleural drainages. All procedures were done as a first-line treatment of empyema. The median length of days with the chest tube in place for empyema cases was 18 days (mean 19.3 days; range 11 to 33 days). In one patient, radiologically guided drainage was performed in a residual posterolateral loculation not drained by a surgical chest tube (after 23 days of surgical chest tube drainage). The radiological chest tube was withdrawn after 16 days with complete resolution of the empyema. Among the other cases, one percutaneous catheter drainage was performed for a postoperative empyema after thoracotomy for lung cancer, which presented with spontaneous empyema drainage through the site of a former surgical chest tube. The pigtail catheter was inserted through the same site. In another patient, a unilateral empyema was treated primarily with a posterior $8 \mathrm{~F}$ ultrasound-guided pigtail catheter (18 days), and then with a $10 \mathrm{~F}$ CT-guided pigtail catheter (14 days) in an anterior residual loculation. The other radiological empyema drainages (where information was available) were carried out with $10 \mathrm{~F}$ catheters. There were two cases of catheter malfunction or plugging, which required catheter replacement. All cases of percutaneous catheter drainage of empyema were successful except one. The patient with unsuccessful pleural percutaneous drainage was a patient with severe dilated cardiomyopathy and end-stage renal failure that presented with bilateral empyemas. Radiological bilateral chest tube placement was followed by fever regression, a slight decrease of white blood cell counts and a significant decrease in the amount of pleural fluid on the right side; however, significant amounts of pleural fluid and fluid output persisted on the left side. Chest tube drainage and other aggressive support therapies were discontinued at the patient's request 23 days after chest tube insertion. The patient died two days later. 

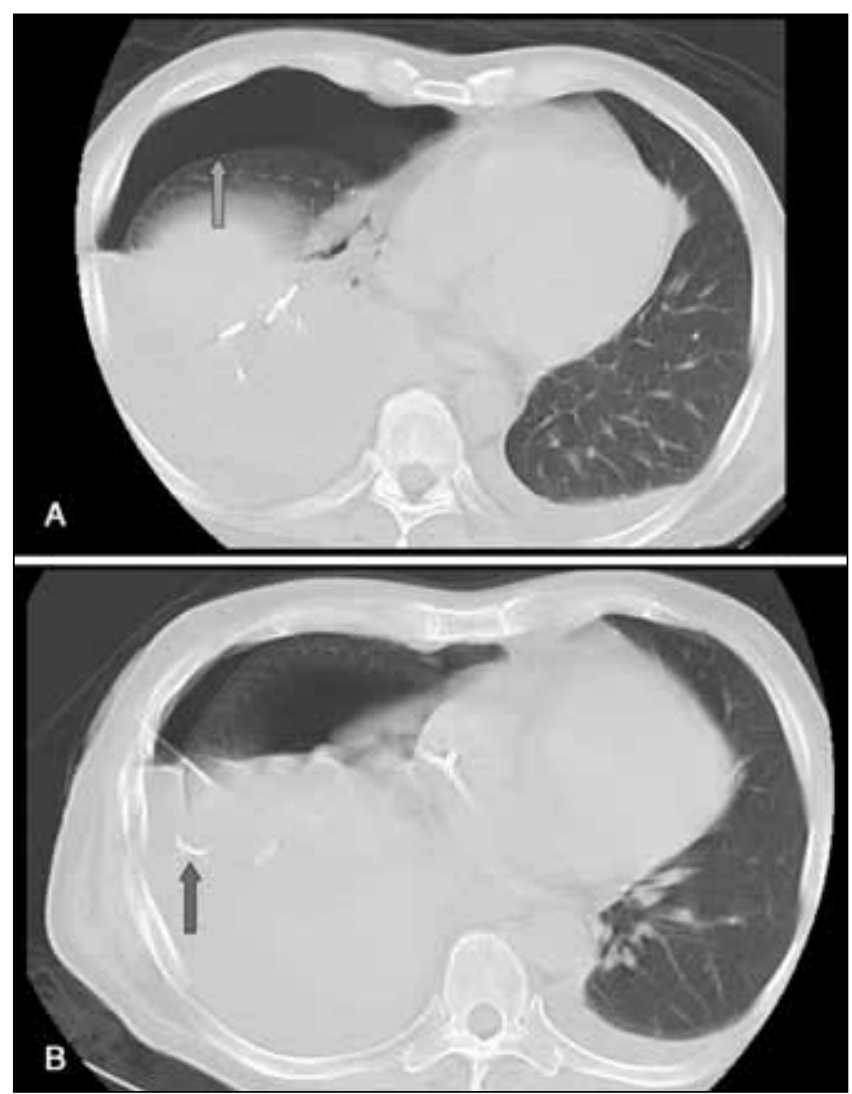

Figure 2) Chest computed tomography scans from a 52-year-old man with liver transplantation. A Right pneumothorax (arrow) following thoracentesis. B A 6 F pigtail pleural tube (arrow) was inserted under computed tomography guidance

Seventeen procedures $(33 \%)$ were associated with good overall clinical evolution. Fifteen interventions (29\%) were performed on patients who died within two months because of their underlying pathology and without any relation to the chest tube drainage. One patient was still hospitalized at the end of the present study. Four procedures $(8 \%)$ were done on patients from an outside centre, and there was no follow-up information available. Finally, in six cases (12\%), a decision was made to restrict all interventions to comfort care, including chest tube withdrawal.

Four radiological chest tubes necessitated replacement by a surgical chest tube for definitive treatment. Regression of chest pathology was demonstrated for all the other radiological chest tubes placed in primary intention. On the other hand, five radiological chest tubes were placed in patients who had a previous unsuccessful surgical chest tube. Four of these five procedures were successful (Figure 1).

Complications following chest tube placement during the course of the present study were infrequent and minor. They included pneumothorax (18\%) and small thoracic wall hematomas (4\%). Pneumothoraxes had a mean diameter of $2.2 \mathrm{~cm}$ (ranging from $0.5 \mathrm{~cm}$ to $5.5 \mathrm{~cm}$ ), and only one necessitated a surgical chest tube for its treatment. All others were treated with the radiological chest tube already in place. No hemothorax, infection of the effusion, re-expansion pulmonary edema or death occurred during the present study.

\section{DISCUSSION}

One purpose of the present retrospective study was to evaluate the efficacy of percutaneous pigtail chest tubes placed under imaging guidance. Our results concerning the use of small-bore chest tubes for the treatment of sterile pleural effusion, pneumothorax and empyema are very encouraging. A high percentage of all the radiological drainage procedures were successful $(88 \%)$. This compares favourably with the literature $(1,5,6)$. Ninety per cent (46 of 51 procedures) of the imaging-guided chest drainages in the present study were performed as firstline treatment.

In the specific case of empyema, very low success rates for drainage with small-bore chest tubes have been previously reported by some authors (6). It as been suggested that large surgical chest tubes, instead of image-guided small-bore chest tubes, should be used as primary intention treatment (1). Huang et al (8) mentioned a success rate of $53 \%$ for the drainage of empyema and complicated parapneumonic effusion despite the use of surgical thoracostomy. The remaining $47 \%$ of cases required decortication. On the other hand, Colice and Rubins (7) stated that the initial concern that small-bore tubes might not adequately drain thick pleural fluid has been allayed as their use has increased. In a series of 43 patients with empyemas, image-guided catheter drainage alone was successful in 31 (72\%) (9). The very good empyema resolution rate $(91 \%)$ in the present study supports the idea that smaller chest tubes inserted under radiological guidance can be effective in the definitive treatment of empyema, and can be used in primary intention. However, care should be taken to rapidly consider a more aggressive approach (eg, fibrinolysis, surgical chest tube drainage or decortication) when small-bore catheter drainage of an empyema does not give an adequate result, especially in the presence of very thick empyema fluid.

Aggressive clinical and imaging follow-up is advocated with percutaneous catheter drainage, and daily fluid output measurement, for early recognition of catheter malfunction or residual collection (10). Moreover, Huang et al (8) found that the presence of loculations in pleural effusions was significantly related to the failure of chest tube drainage. While sonography and CT are excellent tools for positioning a chest tube directly for fluid collection, contrast-enhanced chest $\mathrm{CT}$, in particular, is an excellent imaging technique for identifying any residual undrained pleural fluid collection (7). With CT guidance, the chest tube can be repositioned to drain additional loculations or a second tube can be inserted directly into these other loculations. Also, the excellent success rate of the drainage of loculated effusions $(92 \%)$ in the present series shows that loculations are not a contraindication to chest tube installation under radiological guidance. Merriam et al (10) suggested a systematic follow-up CT scan within $48 \mathrm{~h}$ to $72 \mathrm{~h}$ of catheter placement. In our centre, routine imaging follow-up is done with chest radiographs. CT is done in cases with an unfavourable course of clinical, radiological or drainage count data, as described by Silverman et al (9).

In the present study, the overall median length of days with the chest tube in place was seven days (mean 10 days). For empyemas, the median length of days with the chest tube in place was 18 days (mean 19.3 days; range 11 days to 33 days). Silverman et al (9) and Moulton (11) both reported durations of catheter drainage of seven to 26 days in their empyema 
cases. The duration was $24 \mathrm{~h}$ to 20 days (mean nine days) in the series by Merriam et al (10).

The present success rate for patients who had had a previous unsuccessful surgical chest tube, usually inserted without the benefit of CT imaging, shows that percutaneous pigtail catheter under radiological guidance can be tried, even as a secondary intention. Imaging guidance permits adequate location of the chest tube in the residual pleural effusion.

No major complications and few minor complications occurred in the present study, despite multisystemic pathology and coagulopathy in some of the patients. Patz et al (4) reported a postprocedure pneumothorax rate of 30\% compared with $18 \%$ in the present series. A proportion of these pneumothoraxes can be related to noncompliance of the lung secondary to chronic compression ('trapped lung'), with reabsorption after a few days (4). Small percutaneous catheter drainage also appears to be better tolerated by the patients than large chest tube drainage (12).

\section{REFERENCES}

1. Light RW, Rodriguez RM. Management of parapneumonic effusions. Clin Chest Med 1998;19:373-82.

2. Marom EM, Patz EF Jr, Erasmus JJ, McAdams HP, Goodman PC, Herndon JE. Malignant pleural effusions: Treatment with small bore-catheter thoracostomy and talc pleurodesis. Radiology 1999;210:277-81.

3. Klein JS, Schultz S, Heffner JE. Interventional radiology of the chest: Image-guided percutaneous drainage of pleural effusions, lung abscess, and pneumothorax. AJR Am J Roentgenol 1995;164:581-8.

4. Patz EF Jr, Goodman PC, Erasmus JJ. Percutaneous drainage of pleural collections. J Thorac Imaging 1998;13:83-92.

5. Parulekar W, Di Primio G, Matzinger F, Dennie C, Bociek G. Use of small-bore vs large-bore chest tubes for treatment of malignant pleural effusions. Chest 2001;120:19-25.

6. Roberts JS, Bratton SL, Brogan TV. Efficacy and complications of percutaneous pigtail catheters for thoracostomy in pediatric patients. Chest 1998;114:1116-21.
The present study has some limitations. First, it is a retrospective study with a limited number of cases. Not all patients with pleural pathologies were directly referred for percutaneous drainage at the radiology department, and the results from the present series may not be extended to the total population of patients with pleural effusions or pneumothoraxes. Also, the present study cannot compare radiological pigtail chest tube drainage to surgical drainage for success rate nor duration of treatment because there is no surgical control group in the study. Finally, although different radiologists or radiology residents performed the procedures, the overall success rate was very good, with no major complications.

\section{CONCLUSIONS}

Pigtail catheter installation under radiological guidance is a useful method for definitive treatment of sterile pleural effusions, empyema and pneumothoraxes. This technique can be used as a first-line procedure in the majority of cases.

7. Colice GL, Rubins JB. Practical management of pleural effusions. When and how should fluid accumulations be drained? Postgrad Med 1999; 105:67-70,73-7.

8. Huang HC, Chang HY, Chen CW, Lee CH, Hsiue TR. Predicting factors for outcome of tube thoracostomy in complicated parapneumonic effusion or empyema. Chest 1999;115:751-6.

9. Silverman SG, Mueller PR, Saini S, et al. Thoracic empyema: Management with image-guided catheter drainage. Radiology 1988;169:5-9.

10. Merriam MA, Cronan JJ, Dorfman GS, Lambiase RE, Haas RA. Radiographically guided percutaneous catheter drainage of pleural fluid collections. AJR Am J Roentgenol 1988;151:1113-6.

11. Moulton JS. Image-guided management of complicated pleural fluid collections. Radiol Clin North Am 2000;38:345-74.

12. Westcott JL. Percutaneous catheter drainage of pleural effusion and empyema. AJR Am J Roentgenol 1985;144:1189-93. 


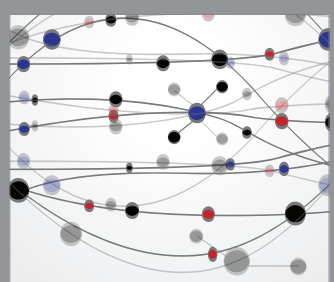

The Scientific World Journal
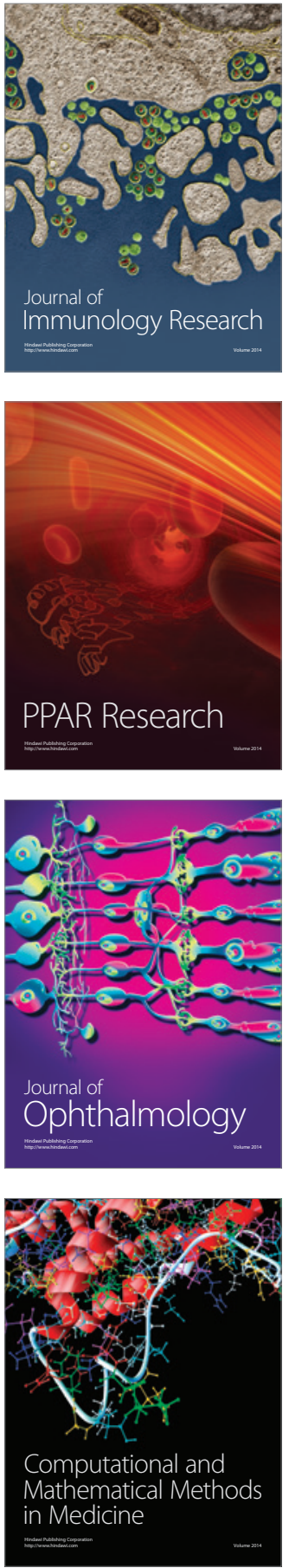

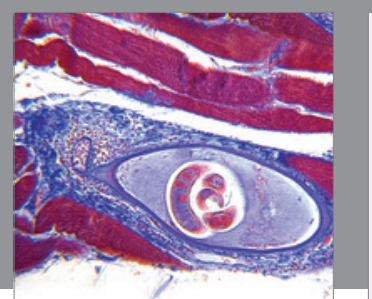

Gastroenterology Research and Practice

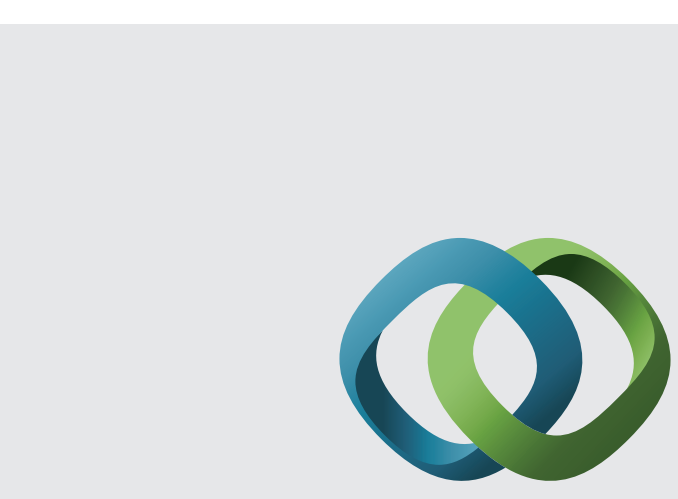

\section{Hindawi}

Submit your manuscripts at

http://www.hindawi.com
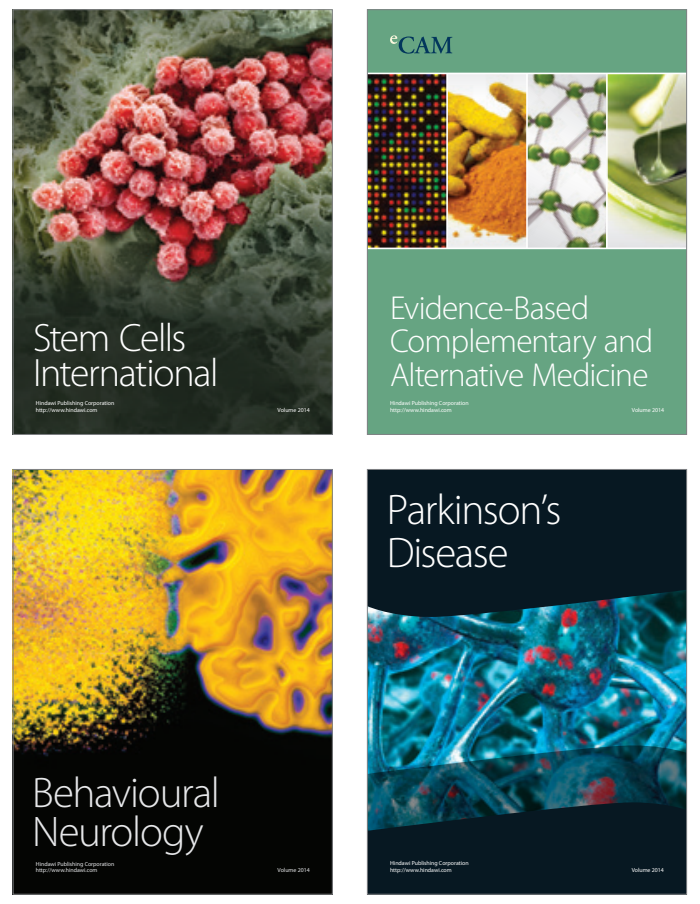
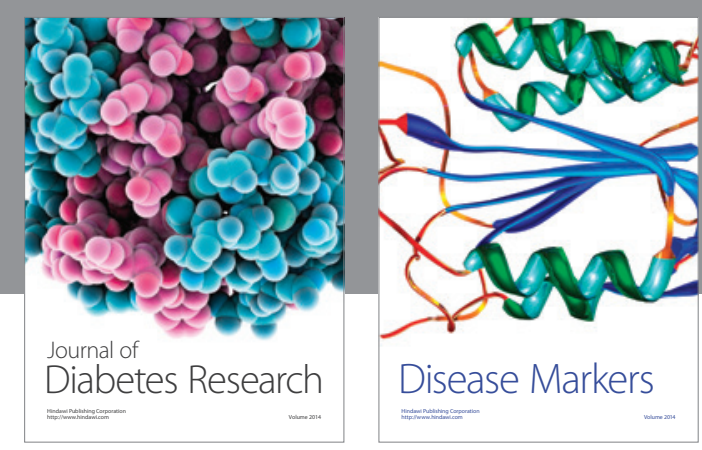

Disease Markers
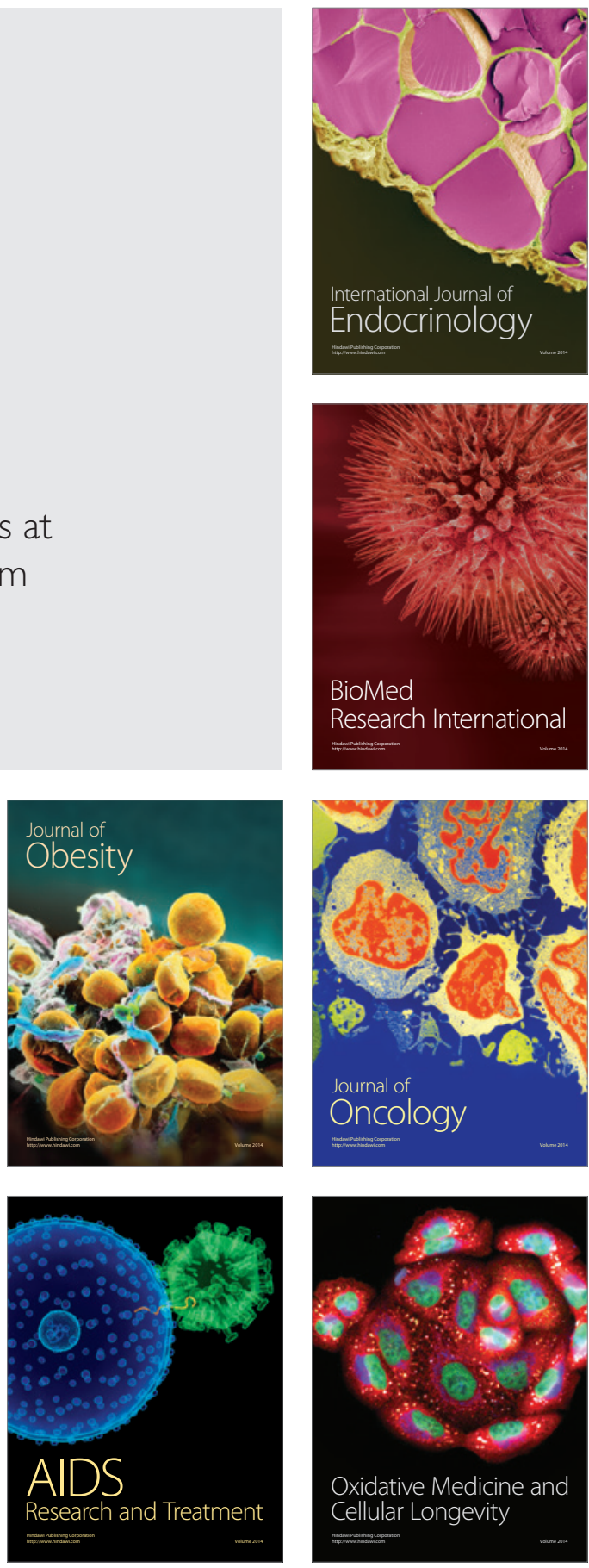